\title{
Microarray profile of circular RNAs identifies hsa_circRNA_102459 and hsa_circRNA_043621 as important regulators in oral squamous cell carcinoma
}

\author{
WEI DENG ${ }^{1 *}$, WEI PENG ${ }^{2 *}$, TAO WANG ${ }^{1}$, JINGXIN CHEN $^{1}$, XUNDING QIU ${ }^{1}$, \\ LIANGBIN FU ${ }^{1}$ and SHUANGXI ZHU ${ }^{2}$
}

\author{
${ }^{1}$ Department of Oral and Maxillofacial Surgery, Hainan General Hospital, Haikou, Hainan 570311; \\ ${ }^{2}$ Department of Oral and Maxillofacial Surgery, The First Affiliated Hospital, \\ Sun Yat-sen University, Guangzhou, Guangdong 510080, P.R. China
}

Received November 12, 2018; Accepted September 12, 2019

DOI: $10.3892 /$ or.2019.7369

\begin{abstract}
Circular RNAs (circRNAs) have emerged as important regulators of carcinogenesis. However, the role of circRNAs in oral squamous cell carcinoma (OSCC) remains limited. Here, total RNAs were extracted from three pairs of OSCC and adjacent normal tissues and subjected to circRNA microarrays to detect the differentially expressed circRNAs. Gene Ontology (GO) and functional category analyses were used to identify circRNAs associated with tumor cell proliferation pathways. Then, gain-of-function assays or loss-of-function assays were conducted to investigate the functions of the most upregulated and downregulated circRNAs on TSCC1 cell proliferation, cell cycle and apoptosis using CCK-8 and EdU assays, flow cytometry and Hoechst 33258 staining, respectively. The results revealed that hsa_circRNA_102459 was significantly downregulated and hsa_circRNA_043621 was significantly upregulated in OSCC tissues. Clinical stage, tumor differentiation, lymph node metastasis presented significant difference in regards to the expression of circRNA_043621 and circRNA_102459. The in vitro experiments further demonstrated that upregulation of circRNA_102459 or downregulation of circRNA_043621 significantly suppressed TSCC1 cell proliferation, induced cell cycle G0/G1 phase arrest and promoted apoptosis. Furthermore, the MAPK and PI3K/Akt pathways were suppressed, while Bcl-2 family members were activated by circRNA_102459
\end{abstract}

Correspondence to: Dr Shuangxi Zhu, Department of Oral and Maxillofacial Surgery, The First Affiliated Hospital of Sun Yat-sen University, 58 Zhongshan 2nd Road, Guangzhou, Guangdong 510080, P.R. China

E-mail: doctorshuangxizhu@163.com

*Contributed equally

Key words: oral squamous cell carcinoma, microarray analysis, circular RNAs overexpression and circRNA_043621 knockdown. Taken together, our study indicates that differentially expressed circRNAs are closely related to the carcinogenesis of OSCC. Among these, circRNA_102459 and circRNA_043621 may function as a tumor-suppressor and promoter, respectively, of OSCC carcinogenesis, and thus may be valuable diagnostic biomarkers of OSCC.

\section{Introduction}

Oral squamous cell carcinoma (OSCC) accounts for more than $90 \%$ of all oral cancers, and is considered as the most frequently diagnosed type of cancer in the head and neck region $(1,2)$. Currently, the 5 year overall survival rate for OSCC has been estimated at approximately 50\% and little improvement has been noted, regardless of the many advances made in surgery, radiation therapy and chemotherapy in the past few decades (3). In addition to the frequent late-stage diagnosis associated with poor patient prognosis, a combination of genetic alterations, environmental risk factors and viral infection results in an increased incidence of OSCC (4). All these factors result in a challenging task for predicting OSCC prognosis. Therefore, it is important to better understand the molecular mechanisms associated with OSCC pathogenesis, so as to develop more effective therapeutic strategies for OSCC patients.

Circular RNAs (circRNAs) are a novel type of endogenous non-coding RNA molecules that regulate gene expression (5). Unlike linear RNA, circRNAs form a closed continuous loop by back-splicing with covalently joined 3'- and 5'-ends (6), which makes it highly stable and largely resistant to RNA degradation (7). This closed structure also presents with advantages for existing as novel molecular biomarkers for many diseases. Increasing evidence indicates that circRNAs play an important role in many diseases, including cardiac senescence (8), atherosclerosis (9) and Alzheimer's disease (10), and especially in human cancers. For example, the expression of hsa circ_0023404 has been shown to be significantly upregulated in cervical cancer (11). CircRNA-Cdrlas exerts anti-oncogenic functions in bladder cancer (12), and hsa_circRNA_103809 
could serve as a prognostic biomarker for patients with lung cancer (13).

Recently, the involvement of circRNAs has also been reported in OSCC. A report has shown that circDOCK1 may target BIRC3 by inhibiting miR-196a-5p to be involved in OSCC development (14). Hsa_circ_100290 has been suggested as a potential prognostic biomarker for OSCC (15). However, these findings are only preliminary and there is a lack of experimental and clinical evidence. With the development of microarray technology, bioinformatic detection tools provide novel insight into a comprehensive analysis of molecular targets involved in tumor progression. The predictive value of circRNAs has been explored in breast cancer by Galasso et al (16) and Nair et al (17).

Hence, we performed circRNA microarray to establish the circRNA expression profile and identified significantly differentially expressed circRNAs between OSCC tissues and paired adjacent non-cancerous tissues. Subsequently, qPCR was used to confirm these differentially expressed circRNAs detected in the microarray. We then selected the most upregulated or downregulated circRNAs to further explore their biological function in OSCC in vitro. The present study provides a molecular basis for investigating the regulatory mechanisms of the circRNAs and highlights their potential as diagnostic and prognostic biomarkers for OSCC patients.

\section{Materials and methods}

Tissue samples and cell culture. Tumor and adjacent tissues ( $2 \mathrm{~cm}$ distant from the tumor margin) were collected from OSCC patients who underwent surgical resection of the primary lesions at Hainan General Hospital (Haikou, Hainan). All of the patients underwent neither chemotherapy nor radiotherapy, and written informed consent was provided by all patients prior to participation. After radical resection, all tissues were snap-frozen in liquid nitrogen and immediately stored at $-80^{\circ} \mathrm{C}$ until use. The histopathological quality of all tissue specimens was independently validated by two licensed pathologists, including the adjacent tissues (histopathological quality of all adjacent tissues were without cancer cells). After histopathological vetting, a total of 23 paired tumor and adjacent tissues were finally included in this study. The microarray chip assay was performed in 3 pairs of OSCC vs. adjacent tissues. The remaining 20 paired tissues were used for verification using quantitative real-time PCR (qPCR). The clinicopathological data of 20 patients is provided in Table I. This study was approved by the Ethics Committee of Hainan General Hospital.

The human OSCC cell line, TSCC1, was obtained from the Cell Bank of Type Culture Collection of Chinese Academy of Sciences (Shanghai, China). TSCC1 cells were cultured in Dulbecco's modified Eagle's medium (DMEM) supplemented with $10 \%$ fetal bovine serum (FBS) (Invitrogen; Thermo Fisher Scientific, Inc.) and maintained in a humidified air atmosphere containing $5 \% \mathrm{CO}_{2}$ at $37^{\circ} \mathrm{C}$.

Total RNA extraction. Total RNA was extracted from the tissue samples using TRIzol reagent (Invitrogen; Thermo Fisher Scientific, Inc.) following the manufacturer's instructions. A NanoDrop 2000 spectrophotometer (NanoDrop; Thermo
Fisher Scientific, Inc.) was used to measure the quantity (ng/ml) and purity (260/280 and 260/230 ratios) of the RNAs. Specifically, OD260/OD280 ratios between 1.8 and 2.1, while OD260/OD230 ratios $>1.8$ were deemed acceptable. RNA integrity and DNA contamination were then assessed through electrophoresis on a denaturing agarose gel.

Sample labeling and hybridization. Sample labeling and array hybridization were performed according to the manufacturer's protocol (Arraystar Inc.). Briefly, Rnase R (Epicentre, Inc.) was used to digest total RNAs in order to degrade any linear RNAs and enrich circular RNAs. These enriched circular RNAs were amplified and transcribed into fluorescent cRNA using a random priming method (Arraystar Super RNA Labeling Kit; Arraystar). The labeled cRNAs underwent purify by RNeasy Mini Kit (Qiagen) and quantitation by NanoDrop ND-1000 (Thermo Fisher Scientific, Inc.). A total of $1 \mu \mathrm{g}$ of each labeled cRNA was fragmented by adding $5 \mu 110 \mathrm{X}$ blocking agent and $1 \mu \mathrm{l}$ of $25 \mathrm{X}$ fragmentation buffer, and then the mixture was heated at $60^{\circ} \mathrm{C}$ for $30 \mathrm{~min}$, and finally diluted by adding $25 \mu \mathrm{l}$ $2 \mathrm{X}$ hybridization buffer. Subsequently, $50 \mu \mathrm{l}$ of hybridization solution was dispensed into the gasket slide and applied to the circRNA expression microarray slide. The slides were incubated for $17 \mathrm{~h}$ at $65^{\circ} \mathrm{C}$ in an Agilent Hybridization Oven (Agilent Technologies, Inc.). The hybridized arrays were washed, fixed and scanned using the Agilent Scanner G2505C (Agilent Technologies, Inc.).

Microarray data analysis. The raw data were extracted by importing the scanned images by Agilent G2565C Microarray Scanner into Agilent Feature Extraction software (version 11.0.1.1; Agilent Technologies, Inc.). R software package limma package (http://bioconductor.riken.jp/packages/3.0/bioc/html/limma.html) was used to carry out a series of data processing including quantile normalization of raw data. Subsequently, differentially expressed circRNAs between the tumor and normal groups were evaluated using t-test, and the P-values were corrected for False Discovery Rate (FDR) by Benjamini-Hochberg (BH) procedure. CircRNAs exhibiting fold changes $\geq 1.5$ and FDR P-values $<0.05$ were considered as significantly differentially expressed.

Hierarchical Clustering was used to show the distinguishable circRNA expression pattern among samples. Scatter plots were performed to evaluate differentially expressed circRNAs with statistical significance between two groups. Volcano Plot filtering was utilized to visualize the significantly differential circRNAs between each pair wise comparison. Hierarchical Clustering, Scatter plots and Volcano Plot filtering were performed using Agilent Feature Extraction software (version 11.0.1.1; Agilent Technologies, Inc.)

Bioinformatic analysis. Gene Ontology (GO) enrichment analysis and Kyoto Encyclopedia of Genes and Functional Categories analysis were performed with the DAVID online tool (https://david.ncifcrf.gov/). GO analysis was performed to annotate genes meaningfully in terms of their biological processes (BP) and molecular functions (MF). The $-\log 10$ (P-value) yields an enrichment score representing the significance of GO term enrichment among differentially expressed genes. Functional Categories analysis was performed to 
Table I. Correlation between hsa_circRNA_043621 and circRNA_102459 expression and clinicopathological characteristics of the 20 patients with oral squamous cell carcinoma.

\begin{tabular}{|c|c|c|c|c|c|c|c|c|}
\hline \multirow[b]{2}{*}{ Characteristics } & \multirow[b]{2}{*}{ Total } & \multicolumn{2}{|c|}{$\begin{array}{l}\text { Expression of hsa } \\
\text { circRNA_043621 }\end{array}$} & \multirow[b]{2}{*}{ P-value } & \multirow[b]{2}{*}{ Total } & \multicolumn{2}{|c|}{$\begin{array}{l}\text { Expression of hsa_ } \\
\text { circRNA_102459 }\end{array}$} & \multirow[b]{2}{*}{ P-value } \\
\hline & & High & Low & & & High & Low & \\
\hline \multicolumn{9}{|l|}{ Sex } \\
\hline Male & 12 & 7 & 5 & \multirow[t]{2}{*}{0.325} & 12 & 8 & 4 & \multirow[t]{2}{*}{0.085} \\
\hline Female & 8 & 3 & 5 & & 8 & 2 & 6 & \\
\hline \multicolumn{9}{|l|}{ Age (years) } \\
\hline$<60$ & 9 & 5 & 4 & \multirow[t]{2}{*}{0.5} & 9 & 3 & 6 & \multirow[t]{2}{*}{0.185} \\
\hline$\geq 60$ & 11 & 5 & 6 & & 11 & 7 & 4 & \\
\hline \multicolumn{9}{|l|}{ Clinical stage } \\
\hline $\mathrm{I}+\mathrm{II}$ & 13 & 9 & 4 & \multirow[t]{2}{*}{0.029} & 13 & 3 & 10 & \multirow[t]{2}{*}{0.017} \\
\hline III+IV & 7 & 1 & 6 & & 9 & 7 & 2 & \\
\hline \multicolumn{9}{|c|}{ Tumor differentiation } \\
\hline Well & 9 & 8 & 1 & \multirow[t]{3}{*}{0.02} & 9 & 2 & 7 & \multirow[t]{3}{*}{0.011} \\
\hline Moderately & 5 & 1 & 4 & & 5 & 2 & 3 & \\
\hline Poorly & 6 & 1 & 5 & & 6 & 6 & 0 & \\
\hline \multicolumn{9}{|c|}{ Lymph node metastasis } \\
\hline Yes & 12 & 4 & 8 & \multirow[t]{2}{*}{0.034} & 12 & 9 & 3 & \multirow[t]{2}{*}{0.003} \\
\hline No & 8 & 6 & 2 & & 8 & 1 & 7 & \\
\hline
\end{tabular}

Cutoff of expression of hsa_circRNA_043621 was 4.490; cutoff of expression of hsa_circRNA_102459 was 0.297. circRNA, circular RNA.

determine the involvement of target genes in the different biological pathway.

Validation of candidate circRNAs by qPCR. Based on fold change $>2$, we selected the top 20 including 10 most upregulated circRNAs, and all 10 downregulated circRNAs for subsequent validation. Briefly, total RNA was extracted from 20 pairs of OSCC samples and matched adjacent tissues using TRIzol reagent. The cDNAs were synthesized with the Prime-Script RT Reagent kit (TakaraBiotechnology) from $500 \mathrm{ng}$ of total RNA. The qPCR was performed with the ABI 7300 PCR instrument using the SYBR Green (Takara Bio Inc., Dalian, China) detection method with divergent primers, as listed in Table II. The thermal cycling parameters used for amplification were as follows: denaturation at $94^{\circ} \mathrm{C}$ for $2 \mathrm{~min}$, followed by 40 cycles at $94^{\circ} \mathrm{C}$ for $20 \mathrm{sec}, 58^{\circ} \mathrm{C}$ for $20 \mathrm{sec}$ and $72^{\circ} \mathrm{C}$ for $30 \mathrm{sec}$. The reaction was stopped by incubation at $75^{\circ} \mathrm{C}$ for $5 \mathrm{~min}$. GAPDH was used as an internal control. The relative gene expression levels were analyzed by the $2^{-\Delta \Delta \mathrm{Cq}}$ method (18).

Cell transfection. To construct the circRNA_102459 overexpression plasmid, the full-length circRNA_102459 cDNA sequence was amplified and cloned into the pcircRNA 1.2 vector (Invitrogen; Thermo Fisher Scientific, Inc.) and sequenced, named as pcRNA-circRNA_102459 (circRNA_102459), while the mock plasmid served as the control vector. The specific small interfering RNAs (siRNAs) targeting circRNA_0436 21(si-circRNA_043621) and scrambled siRNA control were designed and synthesized by RiboBio Co., Ltd. (Guangzhou, China). All of these plasmids and oligonucleotides were transfected into TSCC1 cells using Lipofectamine 2000 (Invitrogen; Thermo Fisher Scientific, Inc.) according to the manufacturer's instructions. At $48 \mathrm{~h}$ after transfection, cells were harvested and used for the in vitro experiments.

CCK-8 assay. Cell growth status was measured using Cell Counting Kit-8 (CCK-8) reagent (Beyotime, China) according to the manufacturer's instructions. Briefly, $1 \times 10^{5}$ cells were seeded into the wells of a 96 -well plate, each group of TSCC1 cells was collected at $48 \mathrm{~h}$ after transfection. Then, $10 \mu$ l CCK- 8 solution was added into each well and incubation was carried out for $2 \mathrm{~h}$ at $37^{\circ} \mathrm{C}$ in darkness. Finally, the absorbance in each well at $450 \mathrm{~nm}$ was measured using a microplate reader (Bio-Tek, USA). The experiment was conducted in three separate wells for each sample, and performed in triplicate.

5-Ethynyl-2'-deoxyuridine (EdU) staining. Cell proliferation was determined by the Cell-Light EdU DNA Cell Proliferation Kit (RiboBio Co., Ltd.) according to the manufacturer's instructions. Briefly, the transfected cells were seeded in triplicate in 96-well plates at a density of $3 \times 10^{3}$ cells per well, and then exposed to $50 \mathrm{mM} \mathrm{EdU}$ for $2 \mathrm{~h}$ at $37^{\circ} \mathrm{C}$. After collection, the cells were fixed with $4 \%$ formaldehyde at room temperature for $20 \mathrm{~min}$ and incubated with $100 \mu \mathrm{l}$ of 1X Apollo ${ }^{\circledR}$ reaction (Ribobio, Guangzhou, China) for $30 \mathrm{~min}$. The cells were subsequently incubated with DAPI detecting 
Table II. Primers used for qPCR analysis of circRNA and mRNA levels.

\begin{tabular}{|c|c|c|}
\hline Target ID & Primer sequence $5^{\prime}-3^{\prime}$ & PS (bp) \\
\hline hsa_circRNA_102459 & $\begin{array}{l}\text { F: CATCTGGAGGAACAGGACAGT } \\
\text { R: ATAAGCAACTTCTTCACCAGC }\end{array}$ & 125 \\
\hline hsa_circRNA_102034 & $\begin{array}{l}\text { F: ACAAGTCGATGGATTCCTCTCA } \\
\text { R: TCACTCTGTTCTGCTTCTGAGT }\end{array}$ & 148 \\
\hline hsa_circRNA_043621 & $\begin{array}{l}\text { F: CCTGAAGAAGAACCACGAGGA } \\
\text { R: TCAACTCTGTCTCATACTTGGTG }\end{array}$ & 122 \\
\hline hsa_circRNA_101996 & $\begin{array}{l}\text { F: AAGATCTACTGGAACTGTCTTGC } \\
\text { R: GCCTGTCCGTTTAGTTGTTGT }\end{array}$ & 121 \\
\hline hsa_circRNA_102733 & $\begin{array}{l}\text { F: AGGGGGACATATAACAGCTGAA } \\
\text { R: TGTGCACCAATCATGTACCC }\end{array}$ & 120 \\
\hline hsa_circRNA_058819 & $\begin{array}{l}\text { F: CGCTGGGCAGACATACCA } \\
\text { R: CCTTGAGTGCCGTTCACAC }\end{array}$ & 121 \\
\hline hsa_circRNA_066361 & $\begin{array}{l}\text { F: TGTCCGCCTATGGCACG } \\
\text { R: CATGTAAGGTCCCTCCTGAGA }\end{array}$ & 125 \\
\hline hsa_circRNA_101036 & $\begin{array}{l}\text { F: TCCGTCTGTGGATAATGGGAG } \\
\text { R: GGTCTCATGGTAAGCAGGAA }\end{array}$ & 133 \\
\hline hsa_circRNA_100245 & $\begin{array}{l}\text { F: CCCGGACTTCTTATCGTGGA } \\
\text { R: CCCGGACTTCTTATCGTGGA }\end{array}$ & 120 \\
\hline hsa_circRNA_088200 & $\begin{array}{l}\text { F: TCCGGACCAAAACCATCAGT } \\
\text { R: AGATCCCATCGGTAGCCATC }\end{array}$ & 123 \\
\hline hsa_circRNA_003949 & $\begin{array}{l}\text { F: ATGCCAGAAGACTGTCACCAT } \\
\text { R: AAATGAATGCCAAGAAGGCAG }\end{array}$ & 127 \\
\hline hsa_circRNA_100259 & $\begin{array}{l}\text { F: AGACCTGGAAGAACCATCCT } \\
\text { R: CTGCTTTGATTTGCACCAGT }\end{array}$ & 143 \\
\hline hsa_circRNA_100045 & $\begin{array}{l}\text { F: CTATGCAGGGGTGGTCAAC } \\
\text { R: ACTTCAGGCAAACAGGTGCT }\end{array}$ & 128 \\
\hline hsa_circRNA_101217 & $\begin{array}{l}\text { F: GGTGGACCTGTACCTCAACA } \\
\text { R: TTTCAATCCGGCTTTGACGA }\end{array}$ & 123 \\
\hline hsa_circRNA_005882 & $\begin{array}{l}\text { F: CTCTCTGTGCACGACTCTCA } \\
\text { R: AGGTACTCTCTGTTCTTGGCT }\end{array}$ & 155 \\
\hline hsa_circRNA_102068 & $\begin{array}{l}\text { F: CCACCACCTTTGAGAGGGAC } \\
\text { R: TCGGATGAGGTCATTGCTGT }\end{array}$ & 120 \\
\hline hsa_circRNA_037767 & $\begin{array}{l}\text { F: GTGCTGCAGTTCCTAGTCA } \\
\text { R: AGTCCCAAAGCTCTGGTTGTT }\end{array}$ & 120 \\
\hline hsa_circRNA_402901 & $\begin{array}{l}\text { F: AGTTTGGAAAGAGTTGCTGTTA } \\
\text { R: TGATAACTACATCTCAAAGGCAG }\end{array}$ & 127 \\
\hline hsa_circRNA_404462 & $\begin{array}{l}\text { F: TTCCCAGTGGACCAAGGCT } \\
\text { R: TCCTGGCTCATCCCAAGTC }\end{array}$ & 144 \\
\hline hsa_circRNA_405247 & $\begin{array}{l}\text { F: GAAGTCCTTGCCTTGTTCCTGA } \\
\text { R: AACAGAGTTTAGACTGACTTGGC }\end{array}$ & 289 \\
\hline GAPDH & $\begin{array}{l}\text { F: TGTTCGTCATGGGTGTGAAC } \\
\text { R: ATGGCATGGACTGTGGTCAT }\end{array}$ & 154 \\
\hline
\end{tabular}

F, forward; R, reverse; PS, product size; circRNA, circular RNA.

liquid for $10 \mathrm{sec}$ followed by microscopic observation using a fluorescent microscope (magnification x200; Olympus Corp., Tokyo, Japan). The percentage of the EdU-positive relative to the DAPI-positive cells was calculated by ImageJ software (ImageJ bundled with 64-bit Java 1.8.0 112; National Institutes of Health, Bethesda, MD, USA). The experiment was conducted in three separate wells for each sample, and performed in triplicate.

Cell cycle and apoptosis assay. For cell cycle analysis, 5x10 transfected cells were harvested by trypsinization, washed two times with PBS, and then fixed in $75 \%$ ice-cold ethanol 


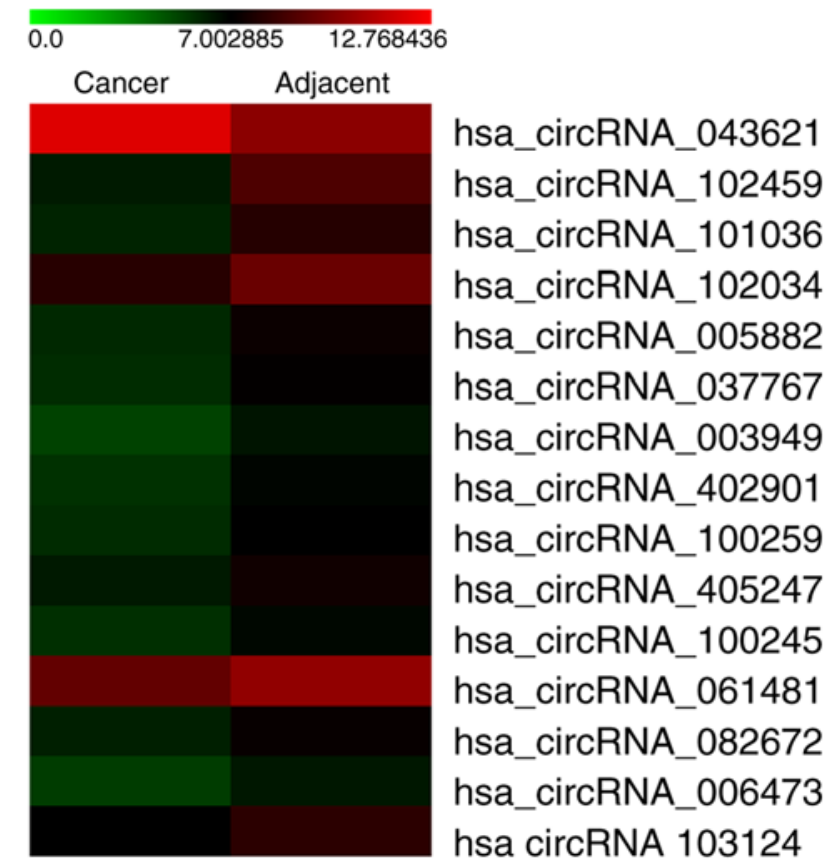

Figure 1. Heatmap of circRNA expression profiles from the microarray in cancer and adjacent tissues. The color scale runs from green (low intensity), through black (medium intensity), to red (strong intensity). circRNA, circular RNA.

overnight at $4^{\circ} \mathrm{C}$. The fixed cells were resuspended in PBS and stained with propidium iodide (PI) $(50 \mu \mathrm{g} / \mathrm{ml})$ containing RNase $(0.1 \mu \mathrm{g} / \mathrm{ml})$. Cell cycle distribution analysis was performed using FACSan flow cytometry (BD Biosciences, San Jose, CA, USA). Data are presented as the percentages of cells in the G0/G1, S and G2/M stages.

Apoptosis analysis was performed using Annexin V-FITC Kit (Abcam, Cambridge, UK). In brief, transfected cells were harvested by trypsinization and resuspended in binding buffer. Then the cells were stained with Annexin V-FITC and PI for $15 \mathrm{~min}$ at room temperature. Cell apoptotic rates were assessed by FACSan flow cytometry (BD Biosciences).

Hoechst 33258 staining. Following cell transfection, cells at the density of $3 \times 10^{5}$ were plated in 6-well plates and further cultured for $12 \mathrm{~h}$. Then cells were washed twice with pre-cooled PBS after the upper culture solution was carefully discarded. Subsequently, cells were fixed with $4 \%$ paraformaldehyde for $10 \mathrm{~min}$ and washed with distilled water, followed by staining with Hoechst 33258 (Thermo Fisher Scientific, Inc.) for $20 \mathrm{~min}$ in the dark. Then, the cells were washed with distilled water, after which the morphology of cells was observed under a fluorescence microscope (magnification x200; Olympus Corp.).

Western blot analysis. Total protein was isolated from cells using RIPA Lysis Buffer (Thermo Fisher Scientific, Inc.). After collecting the supernatants, the protein concentration was determined with a BCA protein assay kit (Bio-Rad Laboratories, Inc.). Equal amounts $(20 \mu \mathrm{g})$ of total protein were separated by $12 \%$ sodium dodecyl sulfate-polyacrylamide gel electrophoresis (SDS-PAGE) and transferred onto PVDF membranes (Millipore). Then, the membranes were blocked with $5 \%$ non-fat dry milk in $1 \mathrm{X}$ TBS containing $0.05 \%$ Tween-20 at room temperature for $1 \mathrm{~h}$. Next, the membranes were incubated with primary antibodies against MAPK (dilution 1:1,000, ab205926; Abcam), PI3K (dilution 1:500; cat. no. ab70912; Abcam), p-PI3K (dilution 1:800, ab182651; Abcam ), AKT (dilution 1:1,000; cat. no. ab8805; Abcam), p-AKT (dilution 1:800; cat. no. ab38449; Abcam), Bcl-2 (dilution 1:1,000; cat. no. ab32124; Abcam), Bax (dilution 1:1000; cat. no. ab32503; Abcam) at $4^{\circ} \mathrm{C}$ overnight and GAPDH (dilution 1:10,000; Cell Signaling Technology) used as internal control. Afterwards, the membranes were incubated with HRP-conjugated secondary antibodies (cat. nos. sc-516102 or sc-2357; Santa Cruz Biotechnology) for $2 \mathrm{~h}$ at room temperature. The protein signal was detected and visualized using an enhanced chemiluminescence reagent (Thermo Fisher Scientific, Inc.). Densitometric quantification was determined using Bio-Rad Quantity One software v.4.6.3 (Bio-Rad Laboratories, Hercules, CA, USA).

Statistical analysis. The fold-change of each circRNA was computed from the profile difference between the cancer and control groups, and the significance was analyzed with a paired t-test. All the in vitro data are expressed as the mean \pm standard deviation (SD) from at least triplicate trials. Statistical analyses were performed by GraphPad Prism 5 (GraphPad Software, Inc., La Jolla, CA, USA). The statistical significance for multi-group comparisons was assessed using one-way ANOVA test with Tukey's test. A P-value $<0.05$ was considered to indicate statistical significance.

\section{Results}

CircRNA expression profiles in OSCC. To study the potential involvement of circRNAs in OSCC, a high throughput circRNA microarray assay was performed in the three pairs of human OSCC and matched normal tissue. Fig. 1 is a hierarchical cluster displaying the circRNA expression pattern in the OSCC and adjacent tissues. The scatter plot of circRNA expression profile was used to describe the variation in circRNA expression between OSCC and adjacent tissues (Fig. 2A). The statistical significance of the differentially expressed circRNAs between the OSCC and adjacent tissues was additionally visualized using volcano plot filtering (Fig. 2B). Based on the filter criteria (fold-change $\geq 1.5$ and a P-value $<0.05$ ), a total of 213 significantly differentially expressed circRNAs were identified, including 124 upregulated and 89 downregulated circRNAs in the OSCC tissues compared with adjacent tissues. Considering that false positives can be caused by multi-comparisons, we used the FDR method to adjust the P-values. After FDR correction, the top 20 differentially expressed circRNAs, including 10 significantly upregulated and 10 significantly downregulated circRNAs were identified, which are listed in Table III.

GO enrichment and functional category analysis. To explore the expression of circRNAs on a more functional level, we performed GO enrichment analysis for the genes involved with the circRNAs that were found to be differentially expressed in the circRNA microarray results. The count number $>2$ and FDR $<0.05$ were chosen as cut-off criteria. The results showed that the most significant enriched GO terms in the biological 
Table III. Top 20 differentially expressed circRNAs in the microarray data in oral squamous cell carcinoma.

\begin{tabular}{|c|c|c|c|c|c|c|}
\hline CircRNAs & P-value & $\log _{2} \mathrm{FC}$ & CircRNA_type & Chrom & Strand & Gene symbol \\
\hline \multicolumn{7}{|l|}{ Upregulated circRNAs } \\
\hline hsa_circRNA_043621 & 0.0245729 & 3.6875525 & Exonic & $\operatorname{chr} 17$ & - & KRT14 \\
\hline hsa_circRNA_101996 & 0.0386753 & 1.9776622 & Exonic & $\operatorname{chr} 17$ & + & SPECC 1 \\
\hline hsa_circRNA_102068 & 0.0396215 & 1.8445549 & Exonic & $\operatorname{chr} 17$ & - & TNS4 \\
\hline hsa_circRNA_088200 & 0.0422007 & 1.7255309 & Exonic & chr9 & - & $T N C$ \\
\hline hsa_circRNA_100045 & 0.0037498 & 1.7117976 & Exonic & $\operatorname{chr} 1$ & - & CTNNBIPI \\
\hline hsa_circRNA_101217 & 0.0185312 & 1.7076297 & Exonic & $\operatorname{chr} 12$ & - & ANKLE2 \\
\hline hsa_circRNA_404462 & 0.0268066 & 1.6557805 & Intronic & chr1 & + & ВC016143 \\
\hline hsa_circRNA_102733 & 0.0416789 & 1.6436409 & Exonic & $\operatorname{chr} 2$ & - & XPO1 \\
\hline hsa_circRNA_058819 & 0.0436044 & 1.6430251 & Exonic & $\operatorname{chr} 2$ & - & COL6A3 \\
\hline hsa_circRNA_066361 & 0.0104826 & 1.6047044 & Exonic & chr3 & + & $F L N B$ \\
\hline \multicolumn{7}{|l|}{ Downregulated circRNAs } \\
\hline hsa_circRNA_102459 & 0.0296076 & -5.6804226 & Exonic & chr19 & + & MAST1 \\
\hline hsa_circRNA_101036 & 0.0239938 & -3.591020 & Exonic & $\operatorname{chr} 12$ & - & TMTC1 \\
\hline hsa_circRNA_102034 & 0.0290761 & -2.8047351 & Exonic & $\operatorname{chr} 17$ & + & RHOT1 \\
\hline hsa_circRNA_005882 & 0.0125354 & -2.6437297 & Exonic & $\operatorname{chr} 2$ & - & STK39 \\
\hline hsa_circRNA_037767 & 0.0191608 & -2.4977462 & Exonic & $\operatorname{chr} 16$ & - & $P P L$ \\
\hline hsa_circRNA_003949 & 0.0116305 & -2.3968409 & Exonic & $\operatorname{chr} 7$ & - & $P T N$ \\
\hline hsa_circRNA_402901 & 0.0435932 & -2.3361872 & Exonic & $\operatorname{chr} 3$ & - & EIF 4E3 \\
\hline hsa_circRNA_100259 & 0.0408402 & -2.3186901 & Exonic & $\operatorname{chr} 1$ & - & WDR78 \\
\hline hsa_circRNA_405247 & 0.0317352 & -2.1636677 & Intronic & $\operatorname{chr} 14$ & + & FUT8 \\
\hline hsa_circRNA_100245 & 0.0160437 & -2.1563291 & Exonic & $\operatorname{chr} 1$ & + & $F G G Y$ \\
\hline
\end{tabular}

FC, fold change; circRNA, circular RNA.
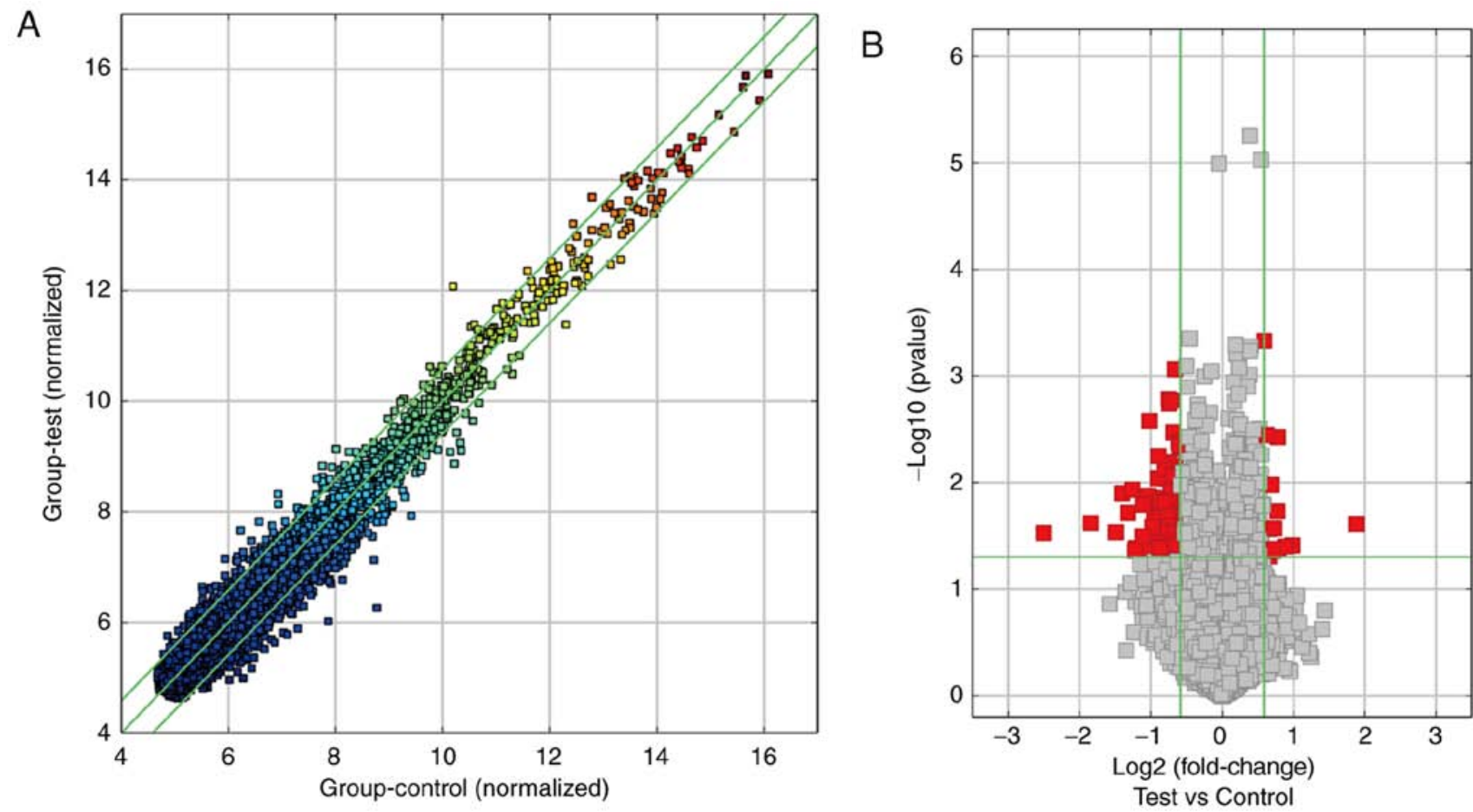

Figure 2. Overview of the microarray signatures. (A) The scatter plot of circRNA signal values shows the circRNA expression variation between the cancer and normal samples. The values spotted in the $\mathrm{x}$ - and $\mathrm{y}$-axes represent the normalized signals of samples in the two groups (log2-scaled). The green lines represent fold-changes. The circRNAs above the upper green line and below the lower green line are those with expression of fold-change $>2.0$ between the cancer and normal-appearing tissues. (B) Volcano plot visualizing the differentially expressed circRNAs between the cancer and normal samples. The vertical green lines correspond to upregulation and downregulation $>2$-fold, and the horizontal line represents $\mathrm{P}=0.05$. The red squares in the plot represent the differentially expressed circRNAs with statistical significance. Test, cancer tissue; Control, adjacent-appearing tissue. circRNA, circular RNA. 
A

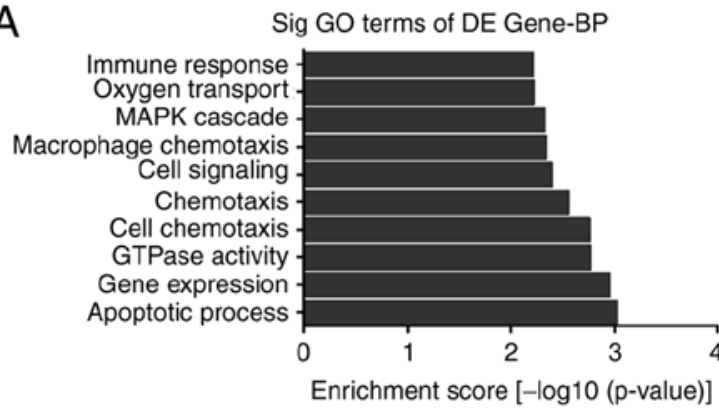

$\mathrm{B}$

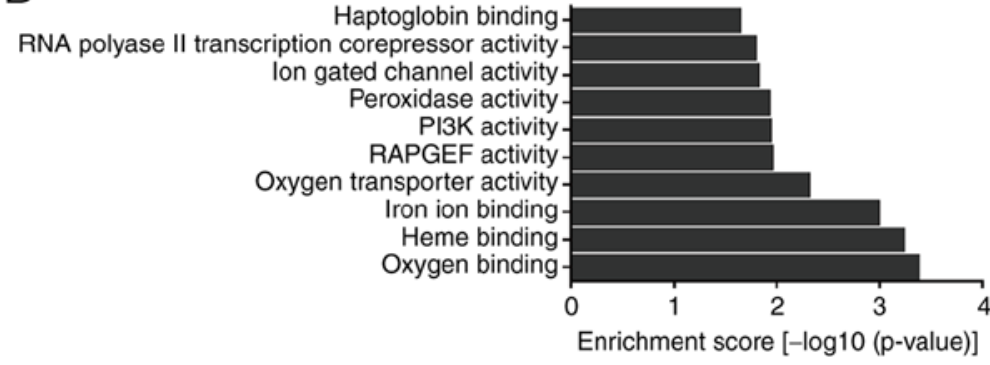

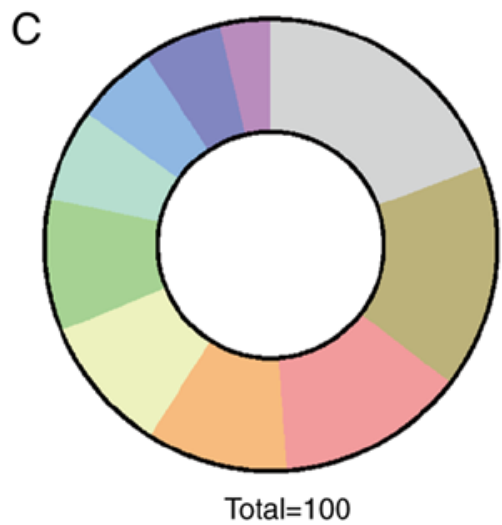

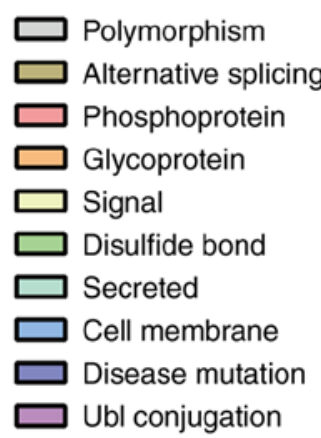

Figure 3. GO enrichment and Functional categories for dysregulated circRNA gene symbols. Most significantly enriched GO (-log10 (P-value)) terms of circRNA gene symbols according to (A) biological process and (B) molecular function. (C) Functional categories of the differentially expressed circRNAs. GO, Gene Ontology; circRNA, circular RNA; BP, biological process; MF, molecular function; DE, differentially expressed.

processes (BP) included 'MAPK cascade', 'cell signaling' and 'apoptotic process' (Fig. 3A). The most significant enriched GO terms in molecular functions (MF) included 'oxygen binding', 'PI3K activity' and 'Heme binding' (Fig. 3B). Functional categories analysis revealed that pathways such as 'phosphoprotein' and 'alternative splicing' were related to the differentially expressed circRNAs (Fig. 3C).

Validation of the deregulated circRNAs. To verify that the differentially expressed circRNAs discovered through the microarray were accurately identified, we selected 20 potentially significant circRNAs involved in the MAPK and PI3K signaling pathways, including 10 upregulated and 10 downregulated circRNAs for validation by qPCR in 20 pairs of human OSCC and matched normal tissues. As expect, the expression patterns of the 10 downregulated (Fig. 4A, $\mathrm{P}<0.001$ ) and 10 upregulated circRNAs (Fig. 4B, $\mathrm{P}<0.001)$ were consistent with the microarray data. Notably, hsa_circRNA_102459 and hsa_circRNA_043621 displayed the lowest and highest expression in the 20 OSCC tissues relative to the normal tissues, respectively, which may play a crucial role in the development and progression of OSCC. In addition, circRNA-miRNA network prediction was conducted, and the results revealed that there are numerous miRNAs that are able to interact with hsa_circRNA_102459 and hsa_circRNA_043621 (Fig. S1).

Table I shows the correlation between circRNA 043621/circ_102459 and the clinicopathological characteristics of the 20 OSCC patients. Specifically, there were no obviously significant correlation between expression and patient age and sex $(\mathrm{P}>0.05)$. However, clinicopathological characteristics, including clinical stage, tumor differentiation and lymph node metastasis presented significant difference in regards to the expression of circRNA_043621 and circRNA_102459 (P<0.05, Table I).

Upregulation of circRNA_102459 or downregulation of circRNA_043621 significantly suppresses OSCC cell proliferation. Next, we performed gain-of-function and loss-of-function assays to evaluate the biological functions of circRNA_102459 and circRNA_043621 in OSCC cells, respectively. As shown in Fig. 5A, qPCR analysis demonstrated that following circRNA_102459 transfection the expression of circRNA_102459 was significantly elevated in the TSCC1 cells $(\mathrm{P}<0.001)$, while si-circRNA_043621 transfection remarkably reduced the expression of circRNA_043621 $(\mathrm{P}<0.001)$ in the TSCC1 cells. Subsequent CCK-8 assay revealed that upregulation of circRNA_102459 and downregulation of circRNA_043621 significantly suppressed the growth of TSCC 1 cells (Fig. 5B, $\mathrm{P}<0.01$ ). In addition, the linear RNA expression levels of circRNA_102459 and circRNA_043621 did not change various to overexpression and knockdown of circRNA_102459 and circRNA_043621 (Fig. S2). Furthermore, 5-ethynyl-2'-deoxyuridine (EdU) staining assay showed that the proliferation potential of TSCC1 cells was impaired upon upregulation of circRNA_102459 or downregulation of circRNA_043621 (Fig. 5C and D, $\mathrm{P}<0.001$ ).

Upregulation of circRNA_102459 or downregulation of circRNA_043621 causes cell cycle G0/G1 phase arrest and promotes apoptosis in OSCC cells. To determine whether the effects of circRNA_102459 or circRNA_043621 on the 
A
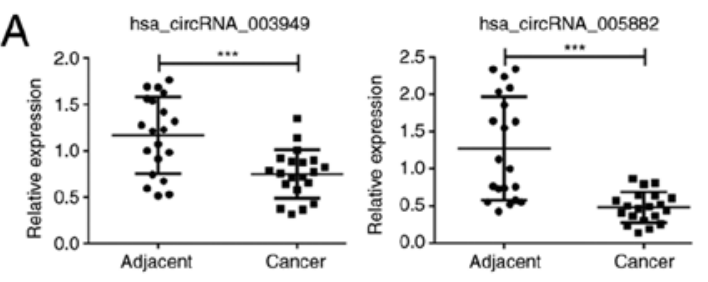

hsa_circRNA_102034
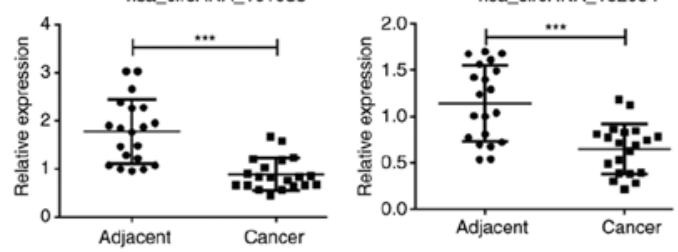

B
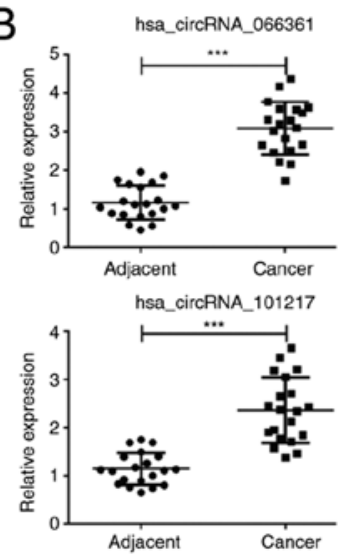

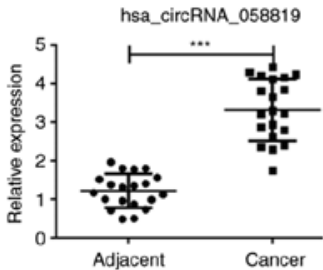

hsa_circRNA_101996

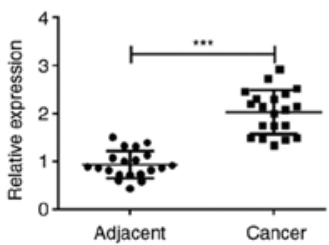

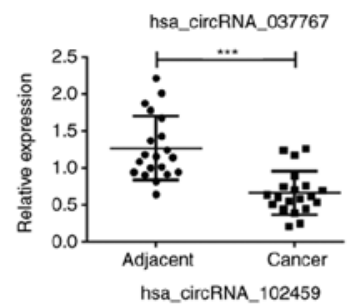
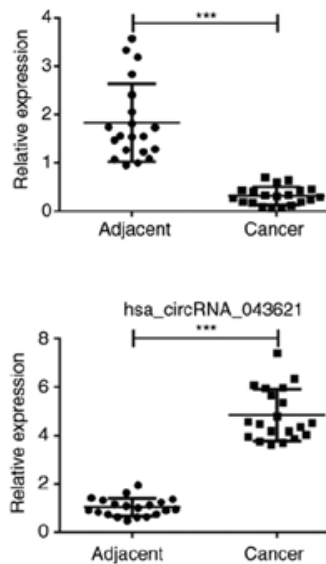

hsa_circRNA_102068

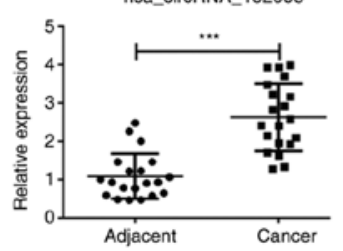

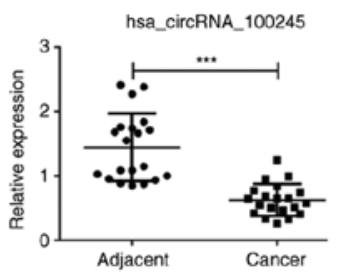

hsa_circRNA_402901
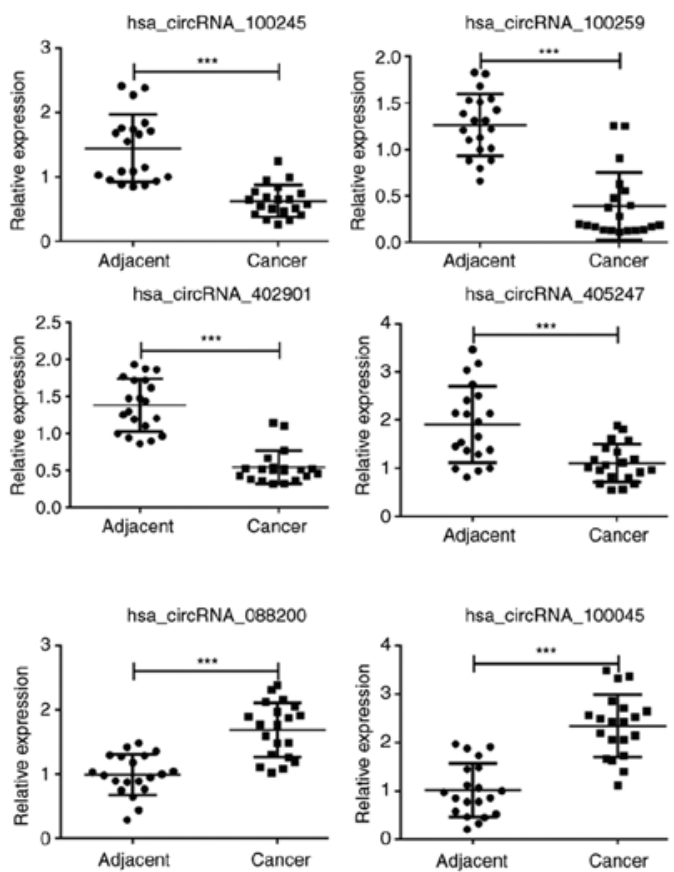

hsa_circRNA_404462
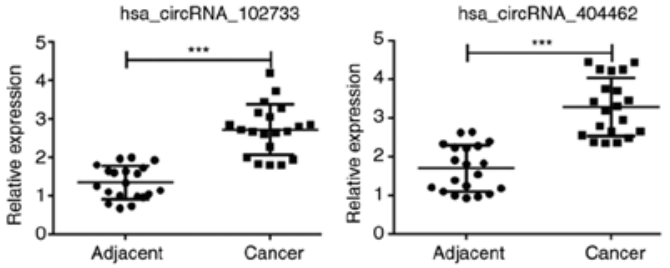

Figure 4. Validation of 20 key circRNAs by qPCR in 20 pairs of OSCC and adjacent tissues. Scatter plots display the relative expression of the (A) 10 downregulated and (B) 10 upregulated circRNAs between cancer and adjacent tissues, which was consistent with the microarray data. ${ }^{* * *} \mathrm{P}<0.001$. circRNAs, circular RNAs; OSCC, oral squamous cell carcinoma; qPCR, real-time quantitative polymerase chain reaction.

proliferation of OSCC cells are mediated by inhibition of cell cycle progression, flow cytometry was used to evaluate the cell cycle distribution in TSCC1 cells. As shown in Fig. 6A, circRNA_102459 overexpression or circRNA_043621 knockdown led to the significant accumulation of cells in the $\mathrm{G} 0 / \mathrm{G} 1-$ phase $(\mathrm{P}<0.01)$ and a significant decrease in cells in the $\mathrm{S}$-phase $(\mathrm{P}<0.01)$ and $\mathrm{G} 2 / \mathrm{M}$-phase $(\mathrm{P}<0.05)$ compared with the corresponding control. Furthermore, the effects of circRNA_102459 or circRNA_043621 on apoptosis were assessed in TSCC1 cells. The percentage of cells undergoing apoptosis, including early apoptosis and late apoptosis, was significantly increased in the circRNA_102459 overexpression or circRNA_043621 knockdown group compared with the corresponding control (Fig. 6B, $\mathrm{P}<0.05$ ). Apoptosis could also be observed when cells were stained with Hoechst 33258 . Here, circRNA_102459 overexpression or circRNA_043621 knockdown induced morphological changes characteristic of apoptosis such as chromatin condensation and nuclear blebbing (Fig. 6C). Taken together, these data suggest that circRNA_102459 overexpression or circRNA_043621 knockdown induces G0/G1 phase arrest and enhances apoptosis in OSCC cells.

CircRNA_102459 and circRNA_043621 mediate the expression of molecules associated with MAPK, PI3K/Akt and apoptotic signaling in OSCC cells. To explore the potential mechanism underlying the role of circRNA_102459 or
circRNA_043621 in cell proliferation, the activation of the MAPK and PI3K/Akt pathways was assessed using western blotting. As shown in Fig. 7, circRNA_102459 overexpression or circRNA_043621 knockdown downregulated the expression of p38 MAPK. The PI3K/Akt pathway was suppressed by circRNA_102459 overexpression or circRNA_043621 knockdown, as revealed by decreased PI3K and Akt phosphorylation. In addition, we found that circRNA_102459 overexpression or circRNA_043621 knockdown obviously reduced anti-apoptotic Bcl-2 expression, but elevated pro-apoptotic Bax expression in the TSCC1 cells.

\section{Discussion}

It is well known that the initiation and progression of OSCC is a complex pathological process. Studies suggest that noncoding circRNAs are potential new diagnostic markers for diseases, especially cancer. To date, several studies have reported that circRNAs function as important regulators in OSCC $(14,15)$. However, the global circRNA expression profile in OSCC has not been fully uncovered.

In the present study, we performed circRNA microarray analysis to identify a number of aberrantly expressed circRNAs in OSCC compared with adjacent tissues. Through GO and Functional categories analysis, a total of 20 significantly differentially expressed circRNAs were screened to be involved in MAPK and PI3K signaling pathways. 


\section{A}

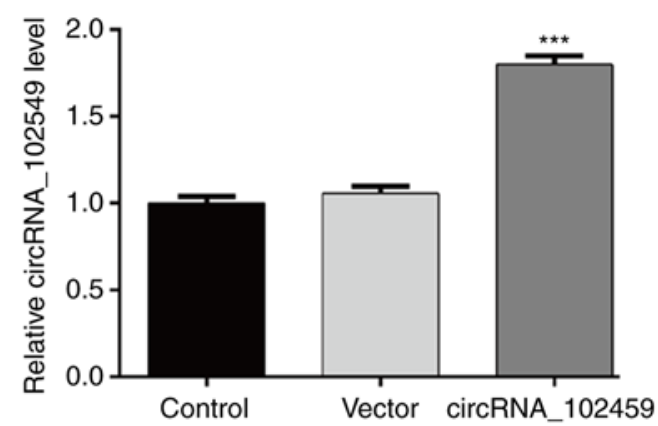

B

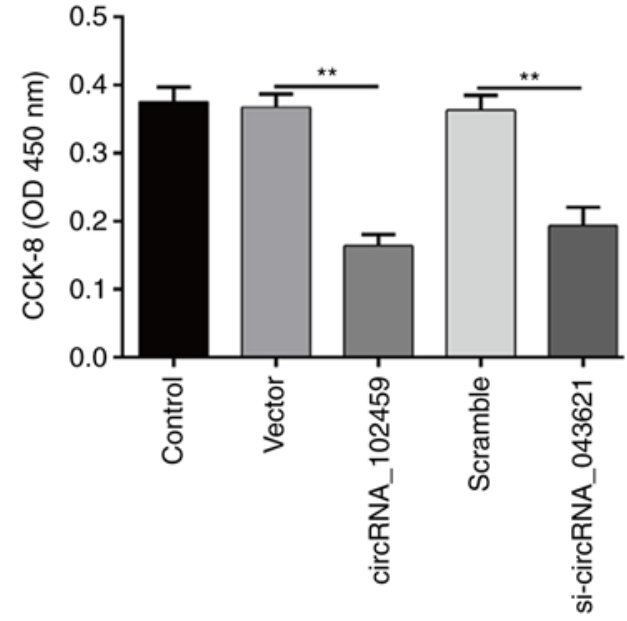

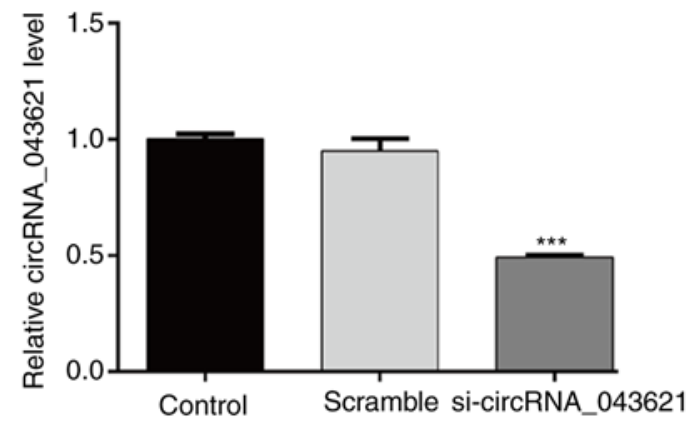

D

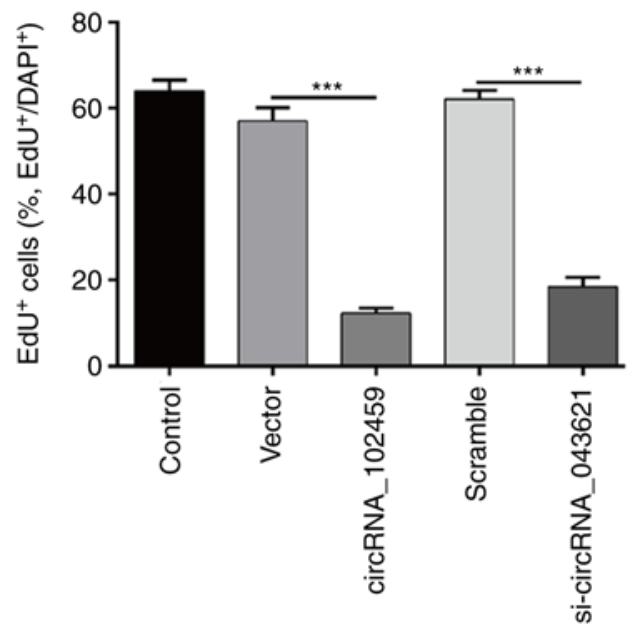

C
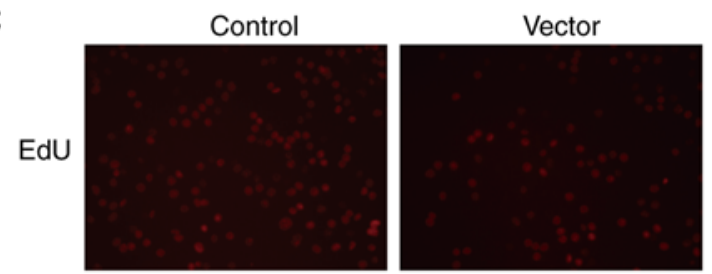

circRNA 102459

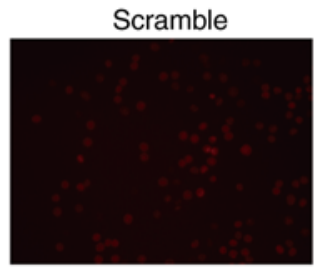

si-circRNA_043621
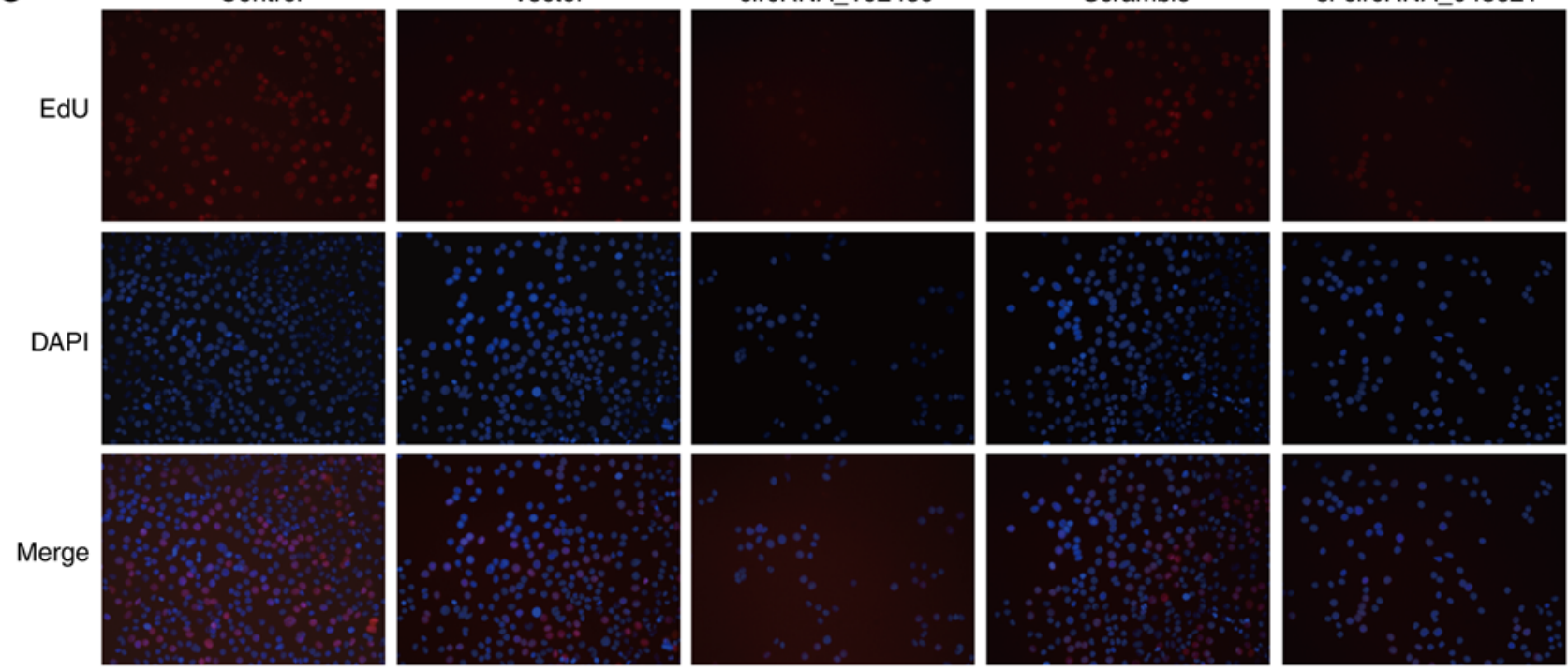

Figure 5. Effects of the upregulation of circRNA_102459 or downregulation of circRNA_043621 on OSCC cell proliferation. TSCC1 cells were transfected with a control vector, circRNA_102459, si-circRNA_043621 or scrambled siRNA, respectively. (A) qPCR analysis demonstrated that the transfection was successful. (B) CCK-8 assay was performed to assess cell proliferation of the TSCC1 following transfection. (C) EdU assay was performed to assess cell proliferation of the TSCC1 following transfection. (D) Quantitation of the EdU-positive TSCC1 cells following transfection from the immunofluorescence results in $\mathrm{C} .{ }^{* *} \mathrm{P}<0.01,{ }^{* * *} \mathrm{P}<0.001$. circRNAs, circular RNAs; OSCC, oral squamous cell carcinoma; qPCR, real-time quantitative polymerase chain reaction.

Accumulating evidence indicates that simultaneous activation of the MAPK and PI3K/AKT pathways is frequently observed to promote the progression of cancers $(19,20)$. We thus utilized qPCR to validate these 20 differentially expressed circRNAs, including 10 upregulated and 10 downregulated circRNAs in another 40 OSCC tissues and paired adjacent normal tissues. As expect, the results of qPCR analysis were consistent with the microarray data, confirming that the microarray data were reliable.

Importantly, hsa_circRNA_102459 and hsa circRNA_043621 were further screened to study their biological function in TCSS1 cells as they displayed the lowest and highest expression in 20 OSCC tissues relative to normal tissues, respectively, which might play a crucial role in the 
A

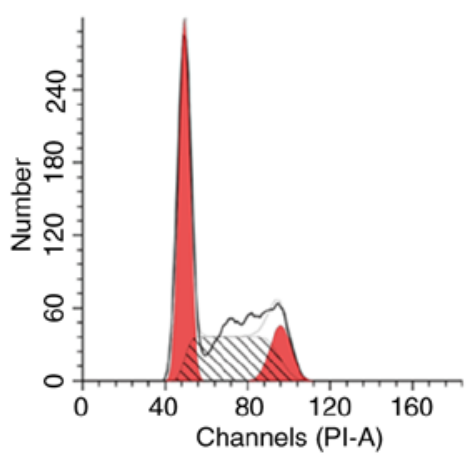

Scramble

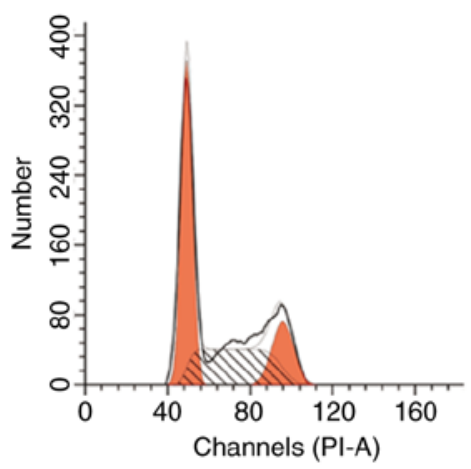

Vector

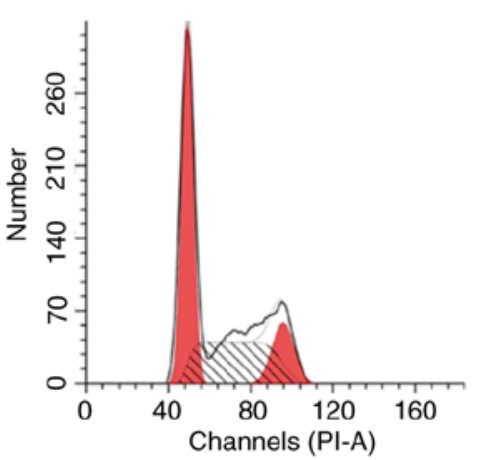

si-circRNA_043621

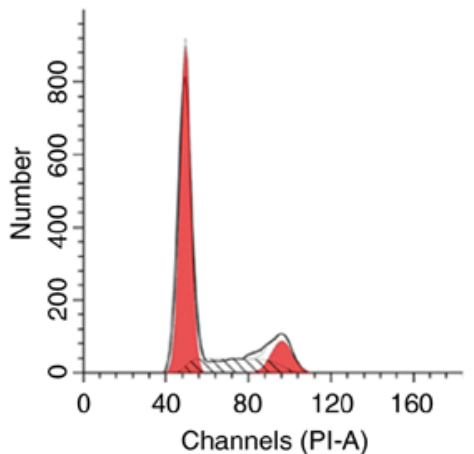

circRNA_102459

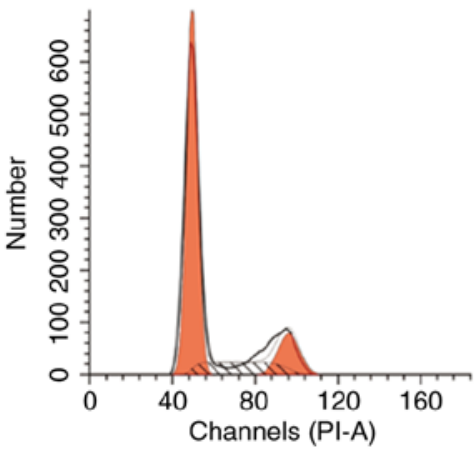

B
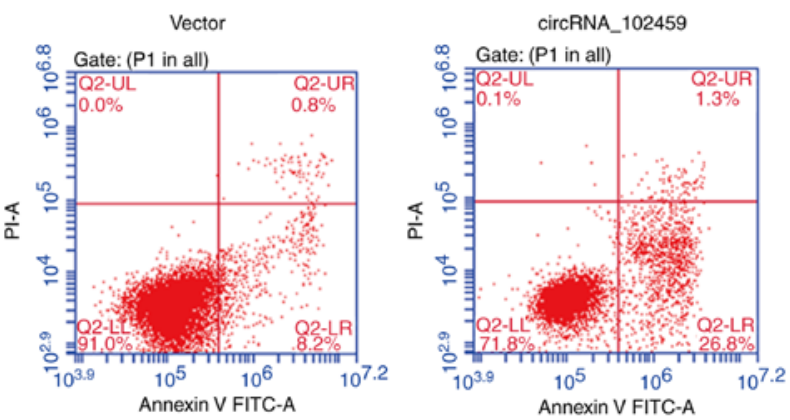

Scramble

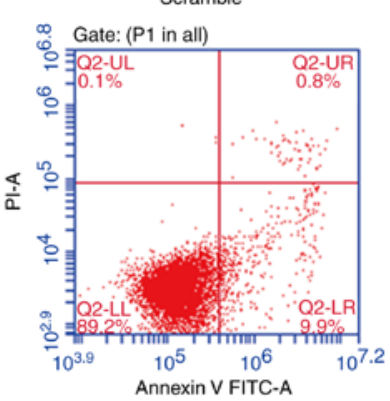

si-circRNA_043621
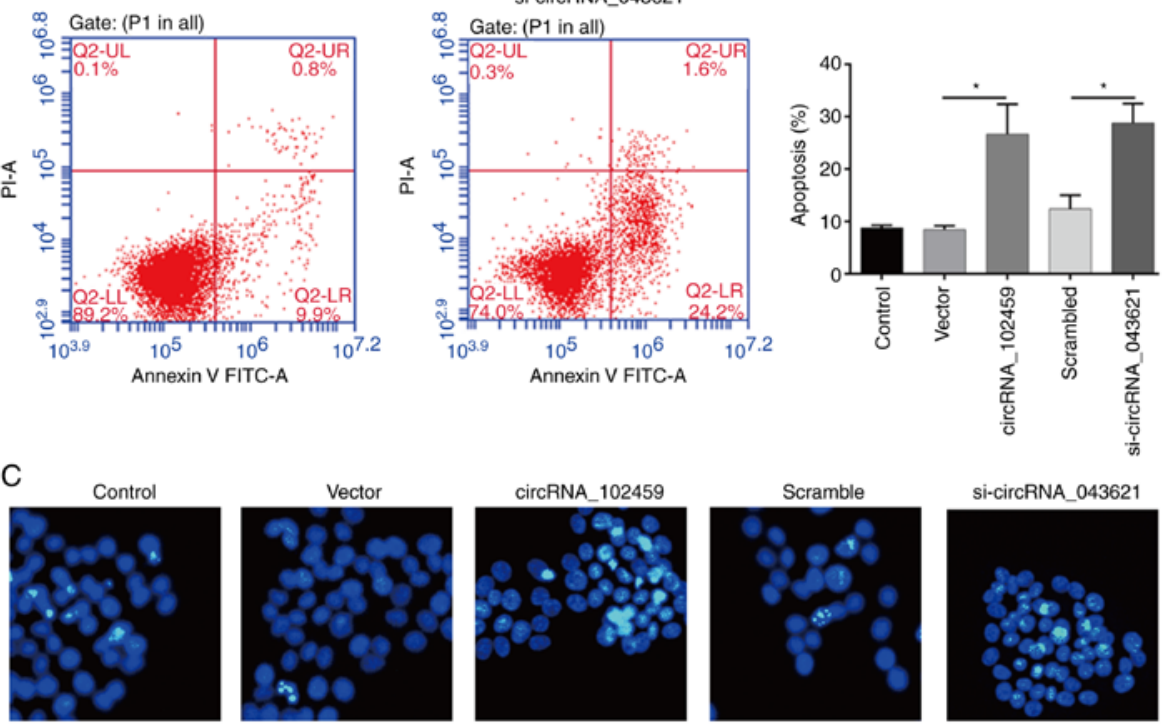

Figure 6. Effects of the upregulation of circRNA_102459 or downregulation of circRNA_043621 on cell cycle progression and apoptosis in OSCC cells. TSCC1 cells were transfected with control vector, circRNA_102459, si-circRNA_043621 or scrambled siRNA, respectively. (A) Cells were collected and labeled with PI and underwent cell cycle analysis by flow cytometry. (B) Cells were collected and labeled with Annexin V-FITC and PI, and underwent apoptotic analysis by flow cytometry. PI, propidium iodide; FITC, fluorescein isothiocyanate. ${ }^{*} \mathrm{P}<0.05,{ }^{* *} \mathrm{P}<0.01$. (C) Hoechst 33258 staining indicates that circRNA_102459 or si-circRNA_043621 transfection led to morphological signs of apoptosis (condensed and fragmented nuclei) in the TSCC1 cells. Morphologic changes were examined under a fluorescence microscope at x200 magnification. circRNAs, circular RNAs; OSCC, oral squamous cell carcinoma. 


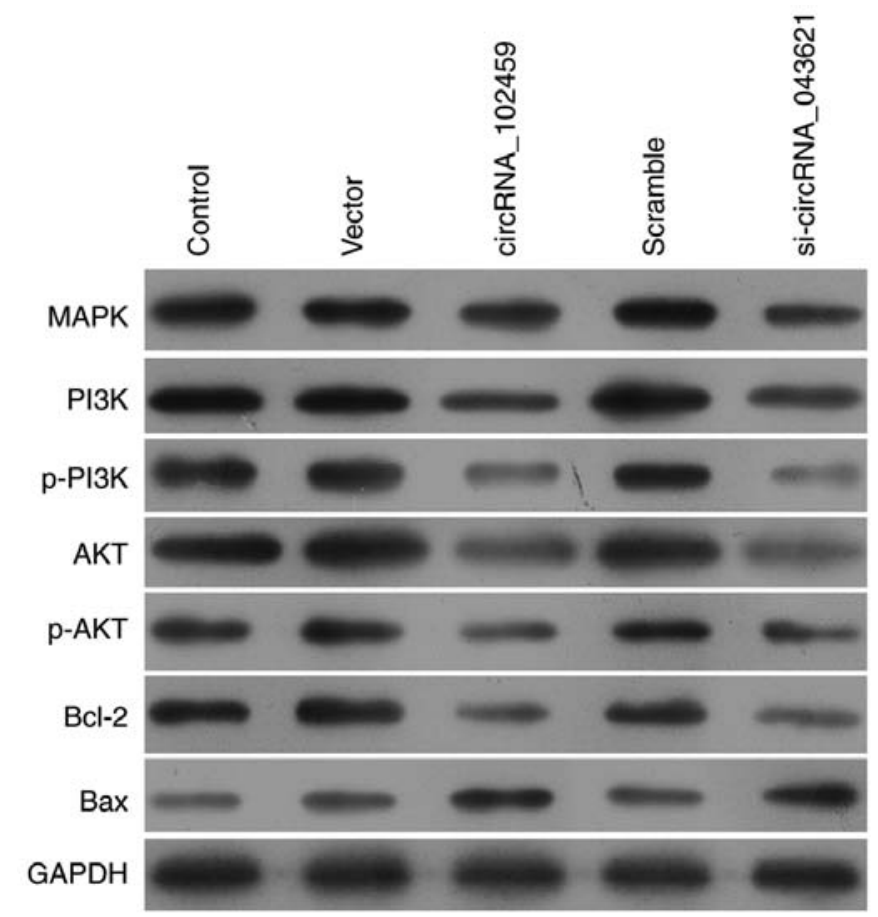

Figure 7. Effects of the upregulation of circRNA_102459 or downregulation of circRNA_043621 on MAPK, PI3K/Akt and apoptotic signaling. TSCC1 cells were transfected with control vector, circRNA_102459, si-circRNA_043621 or scrambled siRNA, respectively. Western blot analysis of p38 MAPK, PI3K, phosphorylated (p)-PI3K, AKT, p-AKT, Bcl-2 and Bax protein levels. GAPDH was used as an internal control.

development and progression of OSCC.Hsa_circRNA_102459 (MAST1) is a member of the MAST family genes and its recurrent gene rearrangements play key roles in subsets of carcinomas (21). Hsa_circRNA_043621 (KRT14) is a valuable hub gene involved in the immune response and tumor cell development in tumorigenesis $(22,23)$. Considering their potential correlation with the progression of tumors, we performed loss-of-function and rescue assays to evaluate the biological functions of circRNA_102459 and circRNA_043621 in OSCC cells, respectively. The results demonstrated that upregulation of circRNA_102459 and downregulation of circRNA_043621 significantly suppressed TSCC1 cell proliferation, induced cell cycle G0/G1 phase arrest and promoted apoptosis, suggesting that circRNA_102459 and circRNA_043621 are closely associated with tumor cell proliferation. However, in the present study, we used only one cell line TSCC1 for our research, and thus this is a limitation of the present study. Two or more cell lines will be used to validate these findings in future research by our group.

The present study further investigated the activation of the MAPK and PI3K/Akt pathways by measuring the phosphorylation of proteins in the MAPK and PI3K/Akt pathways, including p38 MAPK, p-PI3K and p-AKT, in circRNA_102459-overexpressing and circRNA_043621-knockdown TSCC1 cells. When circRNA_102459 was overexpressed, or circRNA_043621 was silenced, the MAPK and PI3K/Akt pathways were suppressed, as presented by decreased p38 MAPK, p-PI3K and p-Akt levels. Consistently, circRNA_043621 (KRT14) was found to be increased upon mortalin overexpression, which is involved in PI3K/Akt signaling contributing to EMT of metastatic cancer (24). In addition, it was found that circRNA_102459 overexpressing and circRNA_043621 silencing significantly upregulated Bcl-2, but downregulated Bax expression in the TSCC1 cells. Apoptosis is a process of programmed cell death and its activation provides a new direction for the treatment of cancer, among which the Bcl-2 family plays a pivotal role in either inhibiting Bcl-2 or promoting Bax expression $(25,26)$. Thus, we infer that circRNA_102459 and circRNA_043621 affect the process of cell apoptosis by influencing changes in Bcl-2 family members.

In summary, the present study provided a profile of circRNAs in OSCC and adjacent tissues. We discovered that circRNA_102459 and circRNA_043621 may function as a tumor suppressor and promoter, respectively, of OSCC carcinogenesis, and thus may be valuable diagnostic biomarkers of OSCC. However, some limitations must be considered in the interpretation of ours results, including the limited sample size and in vivo experimental validation. Therefore, further specific studies are still needed to decipher whether circRNA_102459 and circRNA_043621 participate in cancer-related pathways and sequester miRNAs.

\section{Acknowledgements}

Not applicable.

\section{Funding}

This research was supported by the National Natural Science Foundation of China (no. 81360172).

\section{Availability of data and materials}

The datasets used during the present study are available from the corresponding author upon reasonable request.

\section{Authors' contributions}

SZ contributed to the conception and design of the study. WD and WP performed the experiments. TW and JC completed data analysis and interpretation. XQ and LF contributed to writing the manuscript. All authors read and approved the final manuscript. All authors read and approved the final manuscript and agree to be accountable for all aspects of the research in ensuring that the accuracy or integrity of any part of the work are appropriately investigated and resolved.

\section{Ethics approval and consent to participate}

This study was approved by the Ethics Committee of Hainan General Hospital (Haikou, Hainan, China). Written informed consent was provided by all patients prior to participation.

\section{Patient consent for publication}

Not applicable.

\section{Competing interests}

The authors state that they have no competing interests. 


\section{References}

1. Mignogna MD, Fedele S and Lo Russo L: The world cancer report and the burden of oral cancer. Eur J Cancer Prev 13: 139-142, 2004

2. van Zyl A and Bunn BK: Clinical features of oral cancer. SADJ 67: 566-569, 2012.

3. Blatt S, Kruger M, Ziebart T, Sagheb K, Schiegnitz E, Goetze E, Al-Nawas B and Pabst AM: Biomarkers in diagnosis and therapy of oral squamous cell carcinoma: A review of the literature. J Craniomaxillofac Surg 45: 722-730, 2017.

4. Zhao X, Sun S, Zeng X and Cui L: Expression profiles analysis identifies a novel three-mRNA signature to predict overall survival in oral squamous cell carcinoma. Am J Cancer Res 8: 450-461, 2018

5. Wilusz JE and Sharp PA: Molecular biology. A circuitous route to noncoding RNA. Science 340: 440-441, 2013.

6. Hentze MW and Preiss T: Circular RNAs: Splicing's enigma variations. EMBO J 32: 923-925, 2013.

7. Memczak S, Jens M, Elefsinioti A, Torti F, Krueger J, Rybak A, Maier L, Mackowiak SD, Gregersen LH, Munschauer M, et al: Circular RNAs are a large class of animal RNAs with regulatory potency. Nature 495: 333-338, 2013.

8. Du WW, Yang W, Chen Y, Wu ZK, Foster FS, Yang Z, Li X and Yang BB: Foxo3 circular RNA promotes cardiac senescence by modulating multiple factors associated with stress and senescence responses. Eur Heart J 38: 1402-1412, 2017.

9. Burd CE, Jeck WR, Liu Y, Sanoff HK, Wang Z and Sharpless NE: Expression of linear and novel circular forms of an INK4/ARF-associated non-coding RNA correlates with atherosclerosis risk. PLoS Genet 6: e1001233, 2010.

10. Lukiw WJ: Circular RNA (circRNA) in Alzheimer's disease (AD). Front Genet 4: 307, 2013.

11. Zhang J, Zhao X, Zhang J, Zheng X and Li F: Circular RNA hsa_circ_0023404 exerts an oncogenic role in cervical cancer through regulating miR-136/TFCP2/YAP pathway. Biochem Biophys Res Commun 22: 428-433, 2018.

12. Li P, Yang X, Yuan W, Yang C, Zhang X, Han J, Wang J, Deng X, Yang H, Li P, et al: CircRNA-Cdrlas exerts anti-oncogenic functions in bladder cancer by sponging microRNA-135a. Cell Physiol Biochem 46: 1606-1616, 2018.

13. Liu W, Ma W, Yuan Y, Zhang Y and Sun S: Circular RNA hsa_circRNA_103809 promotes lung cancer progression via facilitating ZNF121-dependent MYC expression by sequestering miR-4302. Biochem Biophys Res Commun 500: 846-851, 2018.

14. Wang L, Wei Y, Yan Y, Wang H, Yang J, Zheng Z, Zha J, Bo P, Tang Y, Guo X, et al: CircDOCK1 suppresses cell apoptosis via inhibition of miR 196a5p by targeting BIRC3 in OSCC. Oncol Rep 39: 951-966, 2018.
15. Chen L, Zhang S, Wu J, Cui J, Zhong L, Zeng L and Ge S: CircRNA_100290 plays a role in oral cancer by functioning as a sponge of the miR-29 family. Oncogene 36: 4551-4561, 2017.

16. Galasso M, Costantino G, Pasquali L, Minotti L, Baldassari F, Corrà $F$, Agnoletto $C$ and Volinia $S$ : Profiling of the predicted circular RNAs in ductal in situ and invasive breast cancer: A pilot study. Int J Genomics 2016: 4503840, 2016.

17. Nair AA, Niu N, Tang X, Thompson KJ, Wang L, Kocher JP, Subramanian S and Kalari KR: Circular RNAs and their associations with breast cancer subtypes. Oncotarget 7: 80967, 2016.

18. Livak KJ and Schmittgen TD: Analysis of relative gene expression data using real-time quantitative PCR and the 2(-Delta Delta $\mathrm{C}(\mathrm{T})$ ) method. Methods 25: 402-408, 2001.

19. Hou P, Liu D, Shan Y, Hu S, Studeman K, Condouris S, Wang Y, Trink A, El-Naggar AK and Tallini G: Genetic alterations and their relationship in the phosphatidylinositol 3-kinase/Akt pathway in thyroid cancer. Clin Cancer Res 13: $1161,2007$.

20. Li S, Ma YM, Zheng PS and Zhang P: GDF15 promotes the proliferation of cervical cancer cells by phosphorylating AKT1 and Erk1/2 through the receptor ErbB2. J Exp Clin Cancer Res 37: 80, 2018

21. Robinson DR, Kalyana-Sundaram S, Wu YM, Shankar S, Cao X, Ateeq B, Asangani IA, Iyer M, Maher CA, Grasso CS, et al: Functionally recurrent rearrangements of the MAST kinase and Notch gene families in breast cancer. Nat Med 17: 1646-1651, 2011.

22. Wang LX, Li Y and Chen GZ: Network-based co-expression analysis for exploring the potential diagnostic biomarkers of metastatic melanoma. PLoS One 13: e0190447, 2018.

23. Zheng Y, Zhao G, Xu B, Liu C, Li C, Zhang X and Chang X: PADI4 has genetic susceptibility to gastric carcinoma and upregulates CXCR2, KRT14 and TNF- $\alpha$ expression levels. Oncotarget 7: 62159-62176, 2016.

24. Na Y, Kaul SC, Ryu J, Lee JS, Ahn HM, Kaul Z, Kalra RS, Li L, Widodo N, Yun CO and Wadhwa R: Stress chaperone mortalin contributes to epithelial-mesenchymal transition and cancer metastasis. Cancer Res 76: 2754-2765, 2016.

25. Yu C, Liu SL, Qi MH, Zou X, Wu J and Zhang J: Herbal medicine guan chang fu fang enhances 5 -fluorouracil cytotoxicity and affects drug-associated genes in human colorectal carcinoma cells. Oncol Lett 9: 701-708, 2015.

26. Brunelle JK and Letai A: Control of mitochondrial apoptosis by the Bcl-2 family. J Cell Sci 122: 437-441, 2009. 